\title{
BMJ Open What is associated with increased side effects and lower perceived efficacy following switching to a generic medicine? A New Zealand cross- sectional patient survey
}

Kate MacKrill, Keith J Petrie

To cite: MacKrill K, Petrie KJ. What is associated with increased side effects and lower perceived efficacy following switching to a generic medicine? A New Zealand cross-sectional patient survey. BMJ Open 2018;8:e023667. doi:10.1136/ bmjopen-2018-023667

- Prepublication history for this paper is available online. To view these files, please visit the journal online (http://dx.doi org/10.1136/bmjopen-2018023667).

Received 18 April 2018 Revised 12 July 2018

Accepted 20 September 2018
Check for updates

(C) Author(s) (or their employer(s)) 2018. Re-use permitted under CC BY-NC. No commercial re-use. See rights and permissions. Published by BMJ.

Department of Psychological Medicine, University of Auckland, Auckland, New Zealand

Correspondence to Professor Keith J Petrie; kj.petrie@auckland.ac.nz

\section{ABSTRACT}

Objective Following a switch from either a generic or branded antidepressant (venlafaxine) to a new generic, we investigated the factors associated with a preference for branded medicines, side effects reported following switching and efficacy ratings of the new generic drug. Design A cross-sectional survey of patients switched to a new generic.

Setting Patients accessing venlafaxine information online from the New Zealand government pharmaceuticals funding website.

Participants 310 patients, comprising 205 originally on branded venlafaxine and 105 previously taking a generic version.

Main outcome measures An online questionnaire assessing demographic factors, perceived sensitivity to medicines, trust in pharmaceutical agencies, sources of switch information, preference for branded medicine, new medicine perceptions, side effects and efficacy ratings.

Results Preference for branded medicine was significantly stronger in older patients $(0 \mathrm{R}=1.04,95 \% \mathrm{Cl}$ 1.01 to 1.05$)$, those taking branded venlafaxine $(0 R=2.02$, $95 \% \mathrm{Cl} 1.13$ to 3.64 ) and patients with a higher perceived sensitivity to medicine $(\mathrm{OR}=1.23,95 \% \mathrm{Cl} 1.06$ to 1.19$)$. Different factors predicted side effects in those switching from the branded and those switching from the generic venlafaxine. Trust in pharmaceutical agencies and the number of side effects were significant predictors of efficacy ratings of the new generic in both patients switching from a branded and those switching from a generic version of venlafaxine.

Conclusions In patients switching from a branded medicine and those already taking a generic, different demographic and psychological factors are associated with preference for branded medicine, side effect reporting and perceived efficacy of the new drug. When switching to new generic, there appears to be a close bidirectional relationship between the experience of side effects and perceived drug efficacy. Trust in pharmaceutical agencies impacts directly on perceived efficacy and increasing such trust could reduce the nocebo response following a generic switch.

\section{Strengths and limitations of the study}

- The study examined both patients on a branded originator as well as those already on a generic switched to a new generic medicine.

- While previous research has used placebo treatments and non-patient participants, our study examined preferences and perceptions in a patient sample that had recently undergone a generic switch in antidepressant medication.

- Our study is limited by the fact that patients were not randomly sampled and whether respondents were actually taking venlafaxine could not be independently corroborated.

\section{INTRODUCTION}

Generic medicines present a cost-effective option for health funders, as they provide the same therapeutic effect as branded medicines, but at a much more affordable price. While generic drugs are now widely used, a significant proportion of the general public, doctors and pharmacists report negative perceptions of generics, in terms of their effectiveness, safety and likelihood to cause side effects. ${ }^{1}$ Many patients believe that generic drugs are not suitable for treating serious conditions, ${ }^{2}$ and there seems greater reluctance to accept generics in patients already established on branded antidepressants compared with other types of medicines. ${ }^{3}$

Negative perceptions of generics can lead to an increase in the nocebo effect following switching from a branded to a generic alternative with greater complaints of side effects and beliefs that the new medication is less effective. ${ }^{4}$ These perceptions can cause increased adverse event reporting, drug refusal and non-adherence when patients are switched from a branded to a generic medicine. ${ }^{5-7}$ Beliefs that the drug is less effective or 
causing side effects can also result in a significant number of patients switching back to the branded medication, resulting in less cost savings for the health system. ${ }^{8}$

There has been little research on the factors associated with a nocebo response following a switch to generic medicine. Previous research suggests patients who have high perceived sensitivity to medicine may be more reluctant to change to a generic and more likely to report side effects. ${ }^{9}$ Trust in pharmaceutical agencies such as drug companies and the government organisations regulating drugs also seem to be important factors in generic acceptance. ${ }^{10}$ A recent study investigating the attribution of symptoms to a placebo described as 'a well-known tablet' found that perceived sensitivity to medicine increased the odds of attributing symptoms to the placebo tablet, while trust in medicines and pharmaceutical companies decreased the likelihood of attributing symptoms. ${ }^{11}$

In 2017, the Pharmaceutical Management Agency (PHARMAC), the New Zealand government agency responsible for subsidising medicines, changed the funded version of the antidepressant venlafaxine. Over the course of 2017, 45000 New Zealanders prescribed either Efexor XR (the branded originator) or Arrow-Venlafaxine XR (a generic version) were switched to a new generic, Enlafax XR. From the outset of the venlafaxine brand switch, some patients reported side effects from the new generic, such as nausea, fatigue, headaches, suicidal thoughts and stated that the drug was not as effective as their previous branded version. Media stories following the switch to generic venlafaxine reflected patient concerns, with article headlines such as 'Patients say generic Pharmac-funded version of antidepressant venlafaxine left them depressed, anxious ${ }^{12}$ and 'Anti-depressant swap: Sufferers claim generic drug is harming their condition'. ${ }^{13}$ This drug switch allowed the opportunity to examine differences between patients switched from an originator brand as well as generic venlafaxine to a new generic version of the antidepressant. The aim of the study was to investigate how both branded and generic groups viewed generic drugs and what factors influenced a preference for branded medicines. We also investigated what factors were associated with side effect reporting following the switch and patients' efficacy ratings of the new generic drug.

\section{METHOD}

\section{Participants and procedure}

Visitors to the venlafaxine brand change page on the PHARMAC website were invited to complete an online questionnaire about their perceptions and experiences of the venlafaxine brand change. To be eligible to participate, respondents had to be 16 years of age or older and currently taking any brand of venlafaxine medication. A link to the survey was provided on the same webpage and was live from 6 March 2017 to 29 October 2017. The survey was anonymous and confidential, with internet protocol addresses and geolocation data from individual responses not recorded. As the survey was anonymous, completion and submission of the questionnaire implied informed consent to participate. This was stated on the participant information page which respondents read before starting the questionnaire.

\section{Measures}

\section{Demographic information}

Participants completed information on age, gender, relationship status, employment status, highest level of education completed and ethnicity.

\section{Venlafaxine brand information and efficacy ratings}

Introductory survey questions collected information on participants' old venlafaxine prescription, specifically the medication brand, time on drug and how participants found out about the brand switch. Participants' perceived efficacy of their old brand and the new generic was assessed using an 11-point scale from 0 'Does not work well' to 10 'Works extremely well' which was developed for this study.

\section{Medication preference}

Participants were asked to consider if given the choice to take a branded or generic version of a prescribed medicine with no difference in cost, which medicine would they prefer to take? Answers were scored 'branded version', 'generic version' or 'no preference'. Participants were also asked to specify, of branded versus generic medicines, which did they expect to be more effective, safe and have fewer side effects. Answers were scored 'branded version', 'generic version' or 'no difference'. They were also asked: 'How often do you look up medication information on the Internet?' assessed using an 11-point scale from 0 'Never' to 10 'Always'. These items have been previously used in a large general population survey. ${ }^{9}$

\section{Trust in pharmaceutical agencies}

Participants were asked to rate how much they trusted brand switch information from pharmacists, PHARMAC, Medsafe and pharmaceutical companies on an 11-point scale from 0 'Do not trust' to 10 'Completely trust'. Participants' scores for these items, which were developed for this study, were summed to create an overall score of trust in pharmaceutical agencies which had an acceptable Cronbach's alpha $(\alpha=0.79)$.

\section{Side effects}

Participants were given a list of 15 frequently reported symptoms (eg, headache, dizziness, chest pain, nausea, abdominal pain ${ }^{14}$ ) and were asked to indicate whether they had experienced any from the new generic venlafaxine within the past week. Answers were scored 'yes', 'maybe' or 'no'. The number of side effects experienced (both yes and maybe) was summed to create a total side effect score. 


\section{Perceived sensitivity to medicines}

The perceived sensitivity to medicines scale ${ }^{15}$ was used to assess participants' self-rated reaction to medicines. The scale consists of five items rated on a 5-point scale from 1 'Strongly Disagree' to 5 'Strongly Agree', an example being 'My body overacts to medicines'. The five items were summed to create a total sensitivity score ranging from 5 to 25, with higher scores indicating a greater perceived sensitivity to the adverse effect of medicines. The scale has shown acceptable reliability and validity in a general population sample ${ }^{9}$ as well as in different patient groups. ${ }^{15} 16$

\section{Statistical analyses}

Analyses were performed using IBSM SPSS V.24. To ascertain what factors influenced a preference for branded medicines, a logistic regression was conducted with medication preference converted to a binary outcome variable of generic or no preference $(0)$ versus a preference for branded medication (1). The predictors in this model were age, gender, education level (dichotomised and dummy coded as university degree 1 or lower 0 ), ethnicity (NZ European 1 or other 0, preswitch medication type (brand 1 or generic 0 ) time on previous venlafaxine brand, participants' perceived efficacy of their old brand, perceived efficacy of the new generic, perceived sensitivity to medicines score, pharmaceutical trust score and the degree to which participants look up medicine information on the internet.

In further analyses, the total sample was separated into two groups: the participants who switched from branded venlafaxine to the new generic and those who switched from the old generic to the new version. Independent sample t-tests and $\chi^{2}$ tests were conducted to investigate whether there were any differences between the brand and generic switch groups on demographic variables, beliefs about the efficacy, safety and side effects of branded and generic medicines, efficacy ratings of the new generic venlafaxine and side effect reports. To investigate what

Table 1 Demographic characteristics for the population of venlafaxine users and comparison between branded and generic switch study samples

\begin{tabular}{|c|c|c|c|c|c|}
\hline & $\begin{array}{l}\text { Population } \\
(n=49175)\end{array}$ & $\begin{array}{l}\text { Brand sample } \\
(\mathrm{n}=205)\end{array}$ & $\begin{array}{l}\text { Generic sample } \\
(n=105)\end{array}$ & & \\
\hline Variable & n (\%) & n (\%) & $\mathrm{n}(\%)$ & $t / \chi^{2}$ & P values \\
\hline Age (mean, SD) & & $45.0(13.16)$ & $44.3(14.18)$ & 0.38 & 0.703 \\
\hline Age group & & & & 5.44 & 0.364 \\
\hline$>19$ years & $1155(2.3)$ & 0 & $1(1.0)$ & & \\
\hline 20-29years & 7309 (14.9) & 27 (13.2) & $20(19.0)$ & & \\
\hline 30-39years & $8202(16.7)$ & $50(24.4)$ & $20(19.0)$ & & \\
\hline 40-49years & $10899(22.2)$ & $50(24.4)$ & $21(20.0)$ & & \\
\hline 50-69years & $16677(33.9)$ & $51(24.9)$ & $26(24.8)$ & & \\
\hline$<70$ years & $4933(10.0)$ & $27(13.2)$ & $17(16.2)$ & & \\
\hline Gender & & & & 0.70 & 0.401 \\
\hline Male & $17478(35.5)$ & $42(20.7)$ & $17(16.7)$ & & \\
\hline Female & $31695(64.5)$ & $161(79.3)$ & 85 (83.3) & & \\
\hline Ethnicity & & & & 0.22 & 0.896 \\
\hline European & $42944(87.3)$ & $184(90.6)$ & 91 (89.2) & & \\
\hline Māori & $4210(8.6)$ & $13(6.4)$ & $8(7.8)$ & & \\
\hline Other & $2021(4.1)$ & $6(3.0)$ & $3(2.9)$ & & \\
\hline Education level & & & & 3.26 & 0.196 \\
\hline Secondary school or below & & $44(22.0)$ & $33(31.4)$ & & \\
\hline Diploma/trade certificate & & $68(34.0)$ & $32(30.5)$ & & \\
\hline University degree & & $88(44.0)$ & $40(38.1)$ & & \\
\hline Relationship status & & & & 5.83 & 0.120 \\
\hline Married, civil union, cohabiting & & $124(61.7)$ & $53(51.5)$ & & \\
\hline Single & & $48(23.9)$ & $32(31.1)$ & & \\
\hline Divorced, separated & & $25(12.4)$ & $18(17.5)$ & & \\
\hline Widow, widower & & $4(2.0)$ & 0 & & \\
\hline
\end{tabular}

$\mathrm{t} / \chi^{2}$ analyses were conducted between the brand sample and generic sample.

Population data were obtained from PHARMAC. 

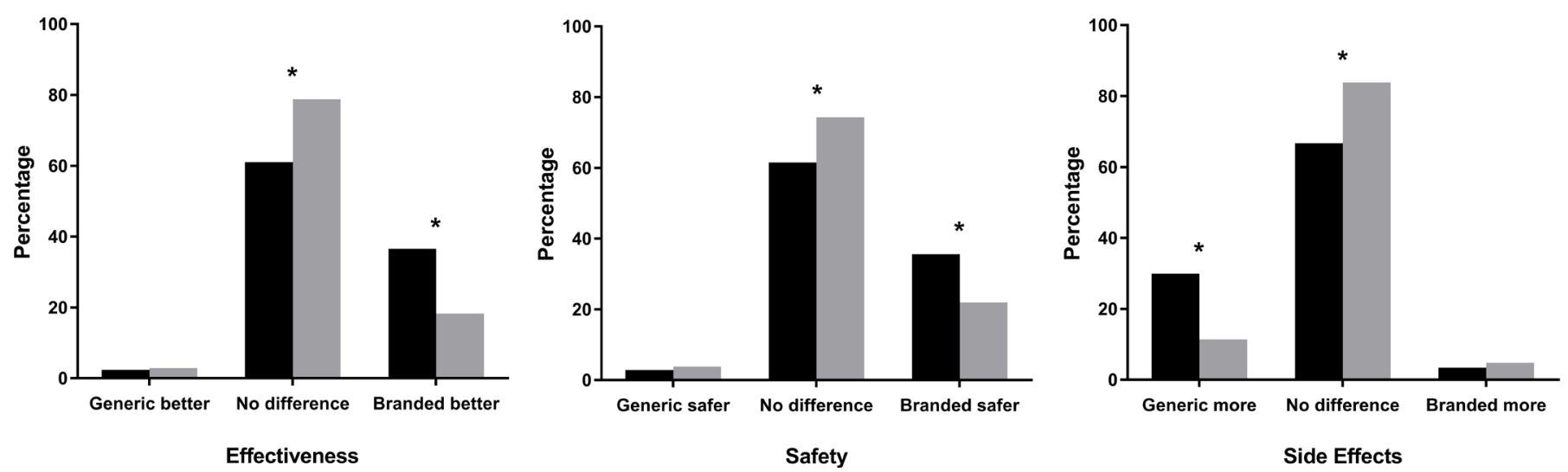

Figure 1 Comparison of the people on branded venlafaxine and those on generic venlafaxine in their beliefs about the efficacy, safety and side effects of branded and generic medicines. ${ }^{*} \mathrm{P}<0.05$.

factors were associated with the two groups' efficacy ratings of the new generic, a multiple linear regression was conducted for each group using participants' efficacy rating of the new generic as the outcome variable. The predictor variables used in these analyses were the same variables used in the analysis of medication preferences, except with the removal of preswitch medication type and new generic efficacy rating and the inclusion of the number of side effects reported. To investigate the factors associated with greater side effect reporting in the two groups, multiple linear regressions were conducted with the side effect score as the outcome variable. The predictor variables used in these models were the same as medication preferences except for the preswitch medication type removed. An alpha level of 0.05 was used for all analyses.

\section{Patient and public involvement}

Patients and the public were not involved in the development and conduct of this study.

\section{RESULTS}

In total, 413 people accessed the survey; however, 103 respondents were excluded: 85 did not complete the survey, 9 did not meet the inclusion criteria and a further 9 participants did not know their original brand of venlafaxine. This resulted in a final sample of 310 participants. The sample was predominantly female $\mathrm{n}=246(79.4 \%)$, with a mean age of 45 years $(\mathrm{SD}=13.50)$. The majority of the sample identified as New Zealand or other European $\mathrm{n}=275(88.7 \%), 21(6.8 \%)$ as Māori and smaller proportions identifying as Asian, Pacific Islander and other ethnicities. The demographic breakdown of the sample is similar to the total population of venlafaxine users in New Zealand, as shown in table 1 . Two hundred and five people were previously on branded venlafaxine, and 105 were taking a generic. There were no significant differences between the two switch groups on demographic variables (table 1 ).

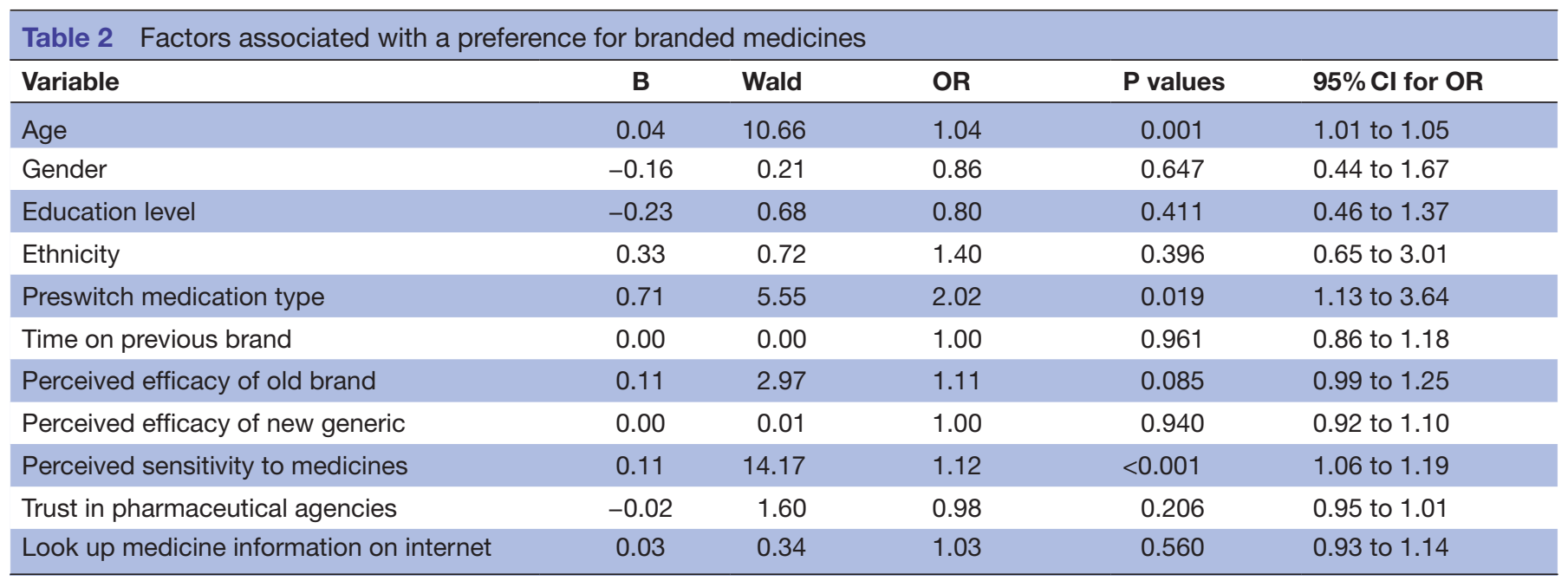


Table 3 Factors associated with the efficacy ratings of the new generic medicine for brand switchers and generic switchers

\begin{tabular}{|c|c|c|c|c|c|c|c|c|}
\hline \multirow[b]{2}{*}{ Variable } & \multicolumn{4}{|c|}{ Brand switchers } & \multicolumn{4}{|c|}{ Generic switchers } \\
\hline & B & $\beta$ & $P$ values & $95 \% \mathrm{Cl}$ for $\mathrm{B}$ & B & $\beta$ & $P$ values & $95 \% \mathrm{Cl}$ for $\mathrm{B}$ \\
\hline Age & -0.01 & -0.03 & 0.656 & -0.04 to 0.03 & 0.02 & 0.07 & 0.457 & -0.03 to 0.06 \\
\hline Gender & 0.53 & 0.07 & 0.304 & -0.48 to 1.54 & -0.98 & -0.12 & 0.187 & -2.44 to 0.48 \\
\hline Education level & -0.78 & -0.13 & 0.079 & -1.66 to 0.09 & -0.58 & -0.09 & 0.339 & -1.77 to 0.62 \\
\hline Ethnicity & -1.16 & -0.13 & 0.086 & -2.49 to 0.17 & 0.03 & 0.00 & 0.966 & -1.44 to 1.51 \\
\hline Time on previous brand & -0.16 & -0.09 & 0.245 & -0.42 to 0.11 & -0.07 & -0.04 & 0.677 & -0.38 to 0.25 \\
\hline Perceived efficacy of old brand & 0.16 & 0.13 & 0.083 & -0.02 to 0.34 & 0.02 & -0.01 & 0.891 & -0.25 to 0.29 \\
\hline Perceived sensitivity to medicines & 0.02 & 0.03 & 0.679 & -0.07 to 0.10 & -0.03 & -0.04 & 0.682 & -0.15 to 0.10 \\
\hline Trust in pharmaceutical agencies & 0.09 & 0.26 & $<0.001$ & 0.04 to 0.13 & 0.18 & 0.45 & $<0.001$ & 0.11 to 0.24 \\
\hline Look up medicine information on internet & -0.02 & -0.01 & 0.854 & -0.18 to 0.15 & -0.01 & -0.01 & 0.959 & -0.22 to 0.21 \\
\hline Number of side effects & -0.17 & -0.24 & 0.002 & -0.28 to -0.07 & -0.27 & -0.33 & $<0.001$ & -0.42 to -0.13 \\
\hline
\end{tabular}

The majority of the sample, $\mathrm{n}=228(73.5 \%)$, found out about the venlafaxine brand switch through a pharmacist, while 45 participants $(14.5 \%)$ said they were not directly told about the switch and only found out after noticing a change in their tablets and 12 people $(3.9 \%)$ were informed of the brand switch by their doctor. The remaining proportion either found out through the PHARMAC website, social media or news media, or friends and family. However, when participants were asked how they would have preferred to have found out about the brand switch, $173(55.8 \%)$ said through their doctor, $86(27.7 \%)$ by a pharmacist and $36(11.6 \%)$ from PHARMAC directly.

\section{Preference for branded or generic medicine}

One hundred and eighty participants $(58.1 \%)$ reported a greater preference for branded medicines overall while $130(41.9 \%)$ preferred generics or had no preference. Compared with the people previously taking a generic, a greater proportion of those originally taking the branded venlafaxine considered branded medicines to be safer, more effective and have fewer side effects than generics (figure 1). Those prescribed generics were more likely to perceive branded and generic medicines as being equivalent in safety, efficacy and the number of side effects.

The analysis of factors influencing people's medicine preferences was significant, $\chi^{2}(12)=44.74, p<0.001$, Nagelkerke $R^{2}=0.20$. The significant factors associated with medicine preference were participants' age, preswitch medication type and perceived sensitivity to medicines. The results indicate that an older age, originally being on the branded venlafaxine medication and a greater perceived sensitivity to medicines is associated with a greater preference for branded medicines overall (table 2).

\section{Efficacy ratings of the new generic}

Both brand and generic switchers rated the efficacy of their old medication very highly (brand switchers $\mathrm{M}=8.46$ out of $10, \mathrm{SD}=2.52$; generic switchers $\mathrm{M}=8.43, \mathrm{SD}=2.16$ ). For the new generic, there were no differences between brand switchers $(\mathrm{M}=3.04, \mathrm{SD}=2.97)$ and generic switchers $(\mathrm{M}=3.46, \mathrm{SD}=3.09)$ in efficacy ratings, $t(299)=-1.17$, $\mathrm{p}=0.244,95 \% \mathrm{CI}-1.14$ to 0.29 . The factors associated with efficacy ratings in the brand and generic switch groups were investigated. The regression model was significant

Table 4 Factors associated with side effect reporting for brand switchers and generic switchers

\begin{tabular}{|c|c|c|c|c|c|c|c|c|}
\hline \multirow[b]{2}{*}{ Variable } & \multicolumn{4}{|c|}{ Brand switchers } & \multicolumn{4}{|c|}{ Generic switchers } \\
\hline & B & $\beta$ & $P$ values & $95 \% \mathrm{Cl}$ for $\mathrm{B}$ & B & $\beta$ & $P$ values & $95 \% \mathrm{Cl}$ for $\mathrm{B}$ \\
\hline Age & 0.06 & 0.18 & 0.017 & 0.01 to 0.10 & 0.01 & 0.04 & 0.671 & -0.05 to 0.07 \\
\hline Gender & 1.41 & 0.14 & 0.047 & 0.02 to 2.79 & -0.96 & -0.10 & 0.347 & -2.99 to 1.06 \\
\hline Education level & -1.61 & -0.20 & 0.008 & -2.81 to -0.42 & -1.04 & -0.13 & 0.210 & -2.68 to 0.60 \\
\hline Ethnicity & -0.39 & -0.03 & 0.680 & -2.23 to 1.46 & -1.23 & -0.12 & 0.229 & -3.24 to 0.79 \\
\hline Time on previous brand & -0.50 & -0.20 & 0.007 & -0.86 to -0.14 & 0.07 & 0.03 & 0.766 & -0.37 to 0.50 \\
\hline Perceived efficacy of old brand & 0.21 & 0.12 & 0.102 & -0.04 to 0.46 & 0.13 & 0.08 & 0.461 & -0.24 to 0.51 \\
\hline Perceived efficacy of new generic & -0.33 & -0.24 & 0.002 & -0.53 to -0.13 & -0.52 & -0.42 & $<0.001$ & -0.79 to -0.24 \\
\hline Perceived sensitivity to medicines & -0.04 & -0.05 & 0.486 & -0.16 to 0.08 & 0.03 & 0.04 & 0.718 & -0.14 to 0.20 \\
\hline Trust in pharmaceutical agencies & -0.01 & -0.02 & 0.760 & -0.07 to 0.06 & 0.06 & 0.13 & 0.245 & -0.04 to 0.17 \\
\hline Look up medicine information on internet & -0.05 & -0.03 & 0.664 & -0.28 to 0.18 & 0.16 & 0.12 & 0.282 & -0.13 to 0.46 \\
\hline
\end{tabular}


for the brand switch group, $\mathrm{F}(10,172)=3.72, \mathrm{p}<0.001$, $\mathrm{R}^{2}=0.18$, and the generic switch group, $\mathrm{F}(10,84)=5.07$, $\mathrm{p}<0.001, \mathrm{R}^{2}=0.38$. For both the brand and generic switch groups, the only variables that were significant predictors of new generic efficacy ratings was the pharmaceutical trust score and number of side effects reported (see table 3). Regardless of whether participants were switching from a branded medicine or a generic, a greater degree of trust in pharmaceutical agencies and fewer side effects reported were associated with a greater perceived efficacy of the new generic venlafaxine.

\section{Side effect reports from the new generic}

There was no significant difference in the brand group $(\mathrm{M}=4.43, \mathrm{SD}=4.07)$ and generic group $(\mathrm{M}=4.85, \mathrm{SD}=3.91)$ in reported side effects following the switch to the new generic, $\mathrm{t}(308)=-0.86, \mathrm{p}=0.392,95 \% \mathrm{CI}-1.36$ to 0.54 . An analysis of the factors associated with greater side effect reporting for brand switchers and generic switchers was conducted and is summarised in table 4 . The regression model of the brand switchers was significant, $\mathrm{F}(10$, $172)=3.61, \mathrm{p}<0.001, \mathrm{R}^{2}=0.17$. Age, gender, education level, duration of time on the old brand and perceived efficacy of the new generic were significantly associated with side effect reporting. The analysis shows that brand switchers who were older, female, had an education level below a university degree, had taken Efexor for a longer period of time and had a lower perceived efficacy of the new generic reported a greater number of side effects from the new generic medication.

The regression model for the generic switchers was also significant $F(10,84)=2.13, p=0.031, R^{2}=0.20$. However, the only significant predictor of side effects for this group was perceived efficacy of the new generic. Generic switchers who had a lower perceived efficacy of the new generic reported more side effects following the switch to the new generic.

\section{DISCUSSION}

\section{Key findings}

In a sample of patients switched to a new generic version of venlafaxine, the study found that preference for branded medication was associated with older age, being on the branded venlafaxine medication prior to the switch and a greater perceived sensitivity to medicines. A greater proportion of patients originally prescribed branded venlafaxine expected branded medicines to be more effective, safe and have fewer side effects than generics, compared with patients taking the generic who were more likely to perceive branded and generic medicines as equivalent. For both patient groups, those switching from the branded medication and those switching from a generic, a greater degree of trust in pharmaceutical agencies and less side effects reported were associated with a higher perceived efficacy of the new generic venlafaxine. For those switching from the branded venlafaxine, being older, female, having a lower education level, being on the branded drug for a longer time and having a lower perceived efficacy of the new generic was associated with reporting a greater number of side effects from the new generic medication. For those patients already on a generic, only a lower perceived efficacy of the new drug was associated with side effect reporting.

\section{Implications}

Switches from originator branded medicines to their generic counterparts provide an economic choice for health funders by enabling more patients to be treated through cost savings. Negative perceptions of generics can cause increased side effects and perceptions of lower efficacy, which may result in non-adherence and low persistence with the new drug and reduce the potential economic benefits of a switch. This study shows that trust in pharmaceutical agencies, including drug companies and regulators, is a key factor in patients' beliefs in the efficacy of the new generic medicine.

Another important finding of the study is the close reciprocal relationship between perceived drug efficacy and reported side effects. The presence of increased side effects are associated with a perception that the drug does not work as well and conversely, low efficacy beliefs are associated with greater reporting of side effects. This is consistent with a recent study that showed when side effects are modelled by another person receiving the same medication (study confederate), this can influence not only reported side effects in the individual viewing the person but also reduce the effectiveness of the drug. ${ }^{17}$

The study also highlights the fact that patients who switch from a branded medicine and those who switch from a generic are likely to have different concerns. Patients already on a generic medicine tend to have a more favourable perception of generics compared with those taking a branded medicine and the factors that influence side effect reports following a medicine brand switch are different for brand switchers compared with generic switchers. People switching from branded medicines are likely to have more difficulties and interventions focused on building trust in pharmaceutical agencies around the switch are likely to have positive effects in influencing the perceived efficacy of the new drug and subsequent side effects. Advertising or education campaigns could aim to build trust around these pharmaceutical monitoring agencies. This could include explaining the level of testing required to establish drug equivalency and the monitoring of that does occur by drug agencies. There may also be an opportunity for intervention by their dispensing pharmacist with patients switching from a branded to generic formulation to reassure patients about these concerns.

\section{Strengths and limitations}

One of the strengths of the study was that it included patients who were switched from branded originator medication and patients on a generic. To our knowledge, this is the first time a study has looked at these groups in 
the same switch to a generic to examine factors related to side effect reporting and efficacy perceptions. Previous research investigating perceptions and responses to medicine change has used placebo tablets and non-patient participants. ${ }^{418}$ The fact that the sample was recruited from the PHARMAC venlafaxine brand change webpage means these patients are likely to be more typical of patients who have concern and difficulties managing a generic switch. A weakness of the study was that patients were not randomly sampled and whether respondents were actually taking venlafaxine or experiencing, the reported side effects could not be independently corroborated.

\section{CONCLUSIONS}

These results suggest that in a switch to a generic drug, different factors are associated with preference for branded medicine, side effect reporting and perceived efficacy of the new drug in patients switching from a branded medicine and those already taking a generic. When switching to a new generic, there appears to be a close bidirectional relationship between the experience of side effects and perceived drug efficacy. Trust in pharmaceutical agencies impacts directly on perceived efficacy and increasing such trust through an explanation of equivalence testing and monitoring could impact on efficacy beliefs, reduce nocebo effects and later non-adherence following a generic switch.

\section{Twitter @KateMacKrill @KeithPetrie}

Contributors KM and KP designed the study, planned the data analysis, interpreted the results and drafted and revised the manuscript. KM collected the data and performed the data analyses. KP is the guarantor.

\section{Funding University of Auckland Doctoral Scholarship}

Competing interests KP has previously received research funding from Pharmac, the New Zealand Government's Pharmaceutical Management Agency.

\section{Patient consent Not required.}

Ethics approval University of Auckland Human Participants Ethics Committee (ref. 018622).

Provenance and peer review Not commissioned; externally peer reviewed.

Data sharing statement № additional data available.

Open access This is an open access article distributed in accordance with the Creative Commons Attribution Non Commercial (CC BY-NC 4.0) license, which permits others to distribute, remix, adapt, build upon this work non-commercially, and license their derivative works on different terms, provided the original work is properly cited, appropriate credit is given, any changes made indicated, and the use is non-commercial. See: http://creativecommons.org/licenses/by-nc/4.0/.

\section{REFERENCES}

1. Colgan S, Faasse K, Martin LR, et al. Perceptions of generic medication in the general population, doctors and pharmacists: a systematic review. BMJ Open 2015;5:e008915.

2. Figueiras MJ, Cortes MA, Marcelino D, et al. Lay views about medicines: the influence of the illness label for the use of generic versus brand. Psychol Health 2010;25:1121-8.

3. Pechlivanoglou P, van der Veen WJ, Bos JH, et al. Analyzing generic and branded substitution patterns in the Netherlands using prescription data. BMC Health Serv Res 2011;11:89-98.

4. Faasse K, Cundy T, Gamble G, et al. The effect of an apparent change to a branded or generic medication on drug effectiveness and side effects. Psychosom Med 2013;75:90-6.

5. Rathe J, Andersen M, Jarbøl DE, et al. Generic switching and nonpersistence among medicine users: a combined population-based questionnaire and register study. PLoS One 2015;10:e0119688.

6. Weissenfeld J, Stock S, Lüngen M, et al. The nocebo effect: a reason for patients' non-adherence to generic substitution? Pharmazie 2010;65:451-6.

7. Zeidan B, Anderson K, Peiris L, et al. The impact of tamoxifen brand switch on side effects and patient compliance in hormone receptor positive breast cancer patients. Breast 2016;29:62-7.

8. Desai RJ, Sarpatwari A, Dejene S, et al. Differences in rates of switchbacks after switching from branded to authorized generic and branded to generic drug products: cohort study. BMJ 2018;361:k1180.

9. Faasse K, Grey A, Horne R, et al. High perceived sensitivity to medicines is associated with higher medical care utilisation, increased symptom reporting and greater information-seeking about medication. Pharmacoepidemiol Drug Saf 2015;24:592-9.

10. Balasopoulos T, Charonis A, Athanasakis K, et al. Why do generic drugs fail to achieve an adequate market share in Greece? Empirical findings and policy suggestions. Health Policy 2017;121:265-72.

11. Webster RK, Weinman J, Rubin GJ. Medicine-related beliefs predict attribution of symptoms to a sham medicine: A prospective study. $\mathrm{Br}$ $J$ Health Psychol 2018;23:436-54.

12. Henry D. Patients say generic Pharmac-funded version of antidepressant venlafaxine left them depressed, anxious. The New Zealand Herald 2018 http://www.nzherald.co.nz/ (accessed 17 Apr 2018).

13. Maude S. Anti-depressant swap: Sufferers claim generic drug is harming their condition. Stuff 2018 https://www.stuff.co.nz (accessed 17 Apr 2018).

14. Petrie KJ, Faasse K, Crichton F, et al. How common are symptoms? Evidence from a New Zealand national telephone survey. BMJ Open 2014;4:005374.

15. Horne R, Faasse K, Cooper V, et al. The perceived sensitivity to medicines (PSM) scale: an evaluation of validity and reliability. $\mathrm{Br} \mathrm{J}$ Health Psychol 2013;18:18-30.

16. Petrie KJ, Moss-Morris R, Grey C, et al. The relationship of negative affect and perceived sensitivity to symptom reporting following vaccination. Br J Health Psychol 2004;9:101-11.

17. Faasse K, Grey A, Jordan R, et al. Seeing is believing: Impact of social modeling on placebo and nocebo responding. Health Psychol 2015;34:880-5.

18. Faasse K, Martin LR, Grey A, et al. Impact of brand or generic labeling on medication effectiveness and side effects. Health Psychol 2016;35:187-90. 